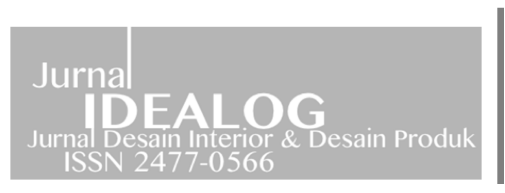

Jurnal IDEA L O G

Jurnal Desain Interior \& Desain Produk

Vol.1 No.1, April 2016

ISSN 2477 - 0566

\author{
Rangga Firmansyah \\ Program Studi Desain Interior \\ Universitas Telkom \\ ranggafirmansyah@tcis.telkomuniversity.ac.id
}

\title{
ADAPTABILITAS PADA JALUR PEDESTRIAN RUSUNAWA PANGGUNGHARJO, SEWON, BANTUL, YOGYAKARTA
}

\begin{abstract}
Abstrak: Rumah susun adalah bangunan gedung bertingkat yang dibangun dalam suatu lingkungan yang terbagi dalam bagian-bagian yang distrukturkan secara fungsional, baik dalam arah horizontal maupun vertikal dan merupakan satuan-satuan yang masing-masing dapat dimiliki dan digunakan secara terpisah, terutama untuk tempat hunian yang dilengkapi dengan bagian bersama, benda bersama, dan tanah bersama.
\end{abstract}

Fokus penelitian mengambil permasalahan pada pola aktivitas yang terjadi di area pedestrian Rusunawa Panggungharjo Blok B sebagai bentuk adaptabilitas penghuni, dengan menggunakan metode penelitian behavior yakni studi tentang hubungan arsitektur dan perilaku dalam kaitannya dengan tata ruang studi kasus area pedestrian dan perilaku berupa pola aktivitas yang terjadi di area pedestrian rumah susun.

Dengan luas yang terbatas terkait fisik bangunan peneliti melihat beberapa fenomena yang ditemukan di Rusunawa Panggungharjo, terjadinya penambahan fungsi selain tempat tinggal, penataan perabot yang kurang sesuai untuk ruang terbatas, dan area pedestrian yang dijadikan tempat aktivitas sosial. Kemampuan lingkungan untuk dapat menampung perilaku berbeda yang belum ada sebelumnya bentuk adaptibilitas pada area pedestrian Rusunawa Panggungharjo.

Kata kunci: Rusunawa, Pedestrian, behaviour study, adaptabilitas

Abstract: Flat-House is rise building built in an environment that is divided into sections structured functionally, either in horizontal or vertical direction and the units that each can be owned and used separately, especially for shelter equipped with parts collective, objects together, and the land collective.

The focus of research taking the problems in the pattern of activity that occurred in the area of pedestrian Rusunawa Panggungharjo Block B as a form of adaptability occupants, using behavior research methods which is the study of the relationship of architecture and behavior in relation to the spatial case study area pedestrian and behavior, a pattern of activity that occurred in pedestrian area flats.

With a limited area of the building physically associated researchers saw some discovered phenomenon in Rusunawa Panggungharjo, the addition of functions in addition to shelter, the arrangement of furniture that are less suitable for confined spaces and pedestrian areas are used as a social activity. The ability of the environment to be able to accommodate different behaviors never before seen in the form adaptibilitas Rusunawa Panggungharjo pedestrian area.

Keywords: Rusunawa, Pedestrian, behavior study, adaptability 


\section{Pendahuluan}

\subsection{Latar belakang}

Keterbatasan lahan dan semakin melambungnya harga tanah di perkotaan, mendorong pilihan pembangunan perumahan ke arah vertikal dalam bentuk rumah susun sederhana (rusuna/flat) bagi masyarakat perkotaan, baik dalam bentuk rumah susun sederhana milik (rusunami) maupun rumah susun sederhana sewa (rusunawa).

Pertumbuhan manusia yang kian pesat menimbulkan kebutuhan akan rumah tinggal bagi manusia. Di berbagai kota besar berbagai macam diupayakan untuk mencegah persoalan kekumuhan dan kesemerawutan kota akibat munculnya daerah-daerah kumu. Salah satunya adalah dengan membangun alternatif rumah vertikal yang lebih dikenal dengan rumah susun. Yogyakarta sebagai salah satu daerah tujuan wisata di Indonesia tidak luput dari fenomena tersebut.

Di Yogyakarta rumah susun sederhana yang disewakan (Rusunawa) merupakan solusi untuk menata pemukiman yang padat dan tidak teratur yang banyak terdapat di tengah kota tersebut, antara lain Rusunawa Kali Code, Rusunawa Jogoyudan. Penelitian mengambil lokasi Rusunawa Panggungharjo, Sewon, Bantul, Yogyakarta yang baru diresmikan kurang lebih pada tahun 2010 .

Dari hasil penelitian ditemukan fenomena adaptabilitas penghuni terhadap keterbatasan seting fisik yang ada pada jalur pedestrian Hal tersebut merupakan wujud dari adaptation by reaction penghuni, namun tidak ada satupun dari penghuni yang melakukan adaptation by adjustmen hal ini dikarenakan kebijakan dari pengelola yang memberikan aturan dan sanksi bila melakukan perubahan fisik dalam bangunan. Jalur pedestrian menjadi area yang perlu dipertimbangkan lagi baik dari sisi seting fisik maupun kebijakan dari pengelola Rusunawa untuk mengatur aktivitas yang terjadi di area pedestrian.

\section{Tinjauan Pustaka}

Dalam kaitannya dengan program peremajaan kota, program pembangunan rumah susun dianggap sebagai cara yang tepat untuk membenahi kampung-kampung kumuh yang lokasinya di bagian kota dengan tingkat kepadatan tinggi, terutama di kota-kota besar. Upaya iniditujukan untuk menciptakan suatu lingkungan perumahan yang baru dan sehat. Menurut Yudohusodo (1991) pembangunan rumah sususn diharapkan dapat menyelesaikan masalahmasalah seperti;penyediaan rumah, efisiensi pengelolaan lingkungan, dan efisiensi biaya operasional oleh penghuni.

\subsection{Rumah susun}

Perkembangan lebih lanjut yang menunjukkan semakin pentingnya pembangunan rumah susun dalam rangka pengadaan perumahan di perkotaan adalah diterapkannya UU no.16 tahun 1985 tentang rumah susun adalah: bangunan gedung bertingkat, terbagi dalam bagian-bagian yang distrukturkan secara fungsional dan vertikal, setiap unitnya dapat dimiliki secara perorangan dan digunakan secara terpisah sebagai tempat hunian yang dilengkapi dengan benda bersama dan tanah bersama. 


\subsection{Aspek-aspek rumah susun}

Aspek-aspek rumah susun terdiri dari lingkungan, unit tempat tinggal, bagian bersama meliputi dinding, taman, tempat parkir, tanah bersama, pemilik, dan perhimpunan penghuni (UU No.16 th.1985, Pasal 1). Menurut UU RI no.06 Th.1985 Pasal3 menyebutkan bahwa manfaat pemabangunan rumah susun adalah menyediakan kebutuhan perumahan yang layak bagi rakyat terutama golongan masyarakat yang berpenghasilan rendah, guna meningkatkan pemerataan kesejahteraan dan pengadilan masyarakat dan guna memanfaatkan tanah perkotaan dengan lingkungan yang bersih dan rapi.

Keputusan menteri perumahan dan pemukiman nomor 10/KPTS/M/1999 tentang kebijakan dan strategi pembangunan rumah susun berdasarkan prioritas kelompok masyarakat sebagai berikut:

1. Rumah susun sederhana milik (rusunami)

2. Rumah susun sederhana sewa tanpa subsidi (rusunawa tanpa subsidi)

3. Rumah susun sederhana sewa bersubsidi (rusunawa bersubsidi)

\subsection{Jalur Pedestrian}

Pedestrian berasal dari bahasa Yunani Pedos yang berarti kaki (Oxford Advance Leraner's Dictionary of Current English, A.S Hornhy dalam seminar TA, FTA Undip 1998). Dalam bahasa Inggris , sebagai kata benda pedestrian berarti "orang yang berjalan kaki” atau sebagai sifat berarti "untuk pejalan kaki (kamus Inggris-Indonesia, Markus, 1996)

Carr (1992) menyebutkan bahwa jalur pedestrian (slidewalks) adalah bagian dari kota di mana orang bergerak dengan kaki, biasanya di sepanjang sisi jalan baik yang direncanakan ataupun terbentuk dengan sendirinya yang menghubungkan satu tempat dengan tempat lainnya. "Bergerak" berasal dari kata gerak yang berarti peralihan tempat atau kedudukan, baik hanya sekali maupun beberapa kali. Bergerak berarti berpindah dari tempat atau keududkan (tidak diam saja) sedangkan pergerakan berarti hal atau keadaan bergerak (kamus Besar Bahasa Indonesia, 1989). Menurut Rapoport (dalam Moudon, 1987) secara Morfologis jalur pedestrian merupakan ruang linier yang digunakan untuk sirkulasi berbagai aktivitas, ruang tersebut terbentuk dengan adanya gedung-gedung di kiri dan kanan jalan. Dari uraian di atas dapat disimpulkan bahwa jalur pedestrian merupalan ruang linier yang digunakan untuk sirkulasi berbagai aktivitas, berjalan dari satu tempat ke tempat lain dan berkaitan erat dengan ruang dan bangunan sekitarnya.

Menurut Lycnh (1974) (dalam Anggraeni, 1999) jalur pedestrian mencakup:

a. fisik, seperti seting jalur, daerah hijau, perabot street furniture

b. fungsi; aktivitas yang terjadi di jalur pedestrian, Eicher dan Tobey (dalam Moudon, 1987) seting fisik jalur pedestrian sebagai salah satu tempat kegiatan parkir, kegiatan informal dan kegiatan manusia (pengguna)

c. Pelaku; Menurut Rapoport (dalam Moudon, 1987) pejalan kaki melakukan kegiatan secara statis dan dinamis.

Maslow (dalam Rutledge, 1985) kebutuhan perilaku pergerakan di jalur pedestrian didasari oleh kedua kelompok kebutuhan dasar manusia, yaitu:

a. Kebutuhan psikologis, tuntutan keselamatan dan relaksasi 
b. Kebutuhan fisiologis, kebutuhan rasa aman, rasa nyaman, fasilitas-fasilitas fisik yang mendukung (makan, minum, kemudahan aksebilitas.

Faktor-faktor yang mempengaruhi pergerakan pejalan kaki

Menurut Moore (1979) faktor yang mempengaruhi pergerakan pejalan kaki yaitu; seting fisik, manusia, pengaruh psikologis.Menurut (Windley,1980, dalam Weisman,1981) kualitas hubungan yang mengkaitkan arsitektur perilaku dan lingkungan, telah mensintensiskan kedalam elemen-elemen atribut lingkungan, yang diantaranya, yaitu: keamanan (aksesbilitas), kenyamanan, sosialisasi.

Berdasarkan kebutuhan dasar tiap individu manusia dan sifat kepribadian (personality) tiap manusia yang berbeda-beda, ada berbagai macam perilaku manusia yang timbul akibat interaksi antar kelompok manusia dan seting tersebut, yaitu (Andrian, 200); bahwa perilaku terhadap seting adalah perilaku manusia yang dipengaruhi oleh seting yang ada.

\subsection{Perilaku}

Dalam studi tentang hubungan arsitektur dan perilaku dalam kaitannya dengan tata ruang, perilaku dioperasionalkan sebagai kegiatan yang membutuhkan setting (tata ruang yang terkait dengan kegiatan) atau wadah kegiatan yang berupa ruang (Haryadi, 1995)

Menurut Weismen (1981), atribut yang muncul dari interaksi manusia dengan lingkungan dapat dirinci menjadi 12 (dua belas) yaitu:
a. Kenyamanan (comfort)
b. Sosialitas (sociality)
c. Visibilitas (visibility
d. Aksesibiltas (accessibility)

e. Adaptabilitas (adaptability) adalah kemampuan lingkungan untuk dapat menampung perilaku berbeda yang belum ada sebelumnya.

f. Rangsangan inderawi (sensory simulation)

g. Kontrol (control)

h. Aktivitas (activity) adalah perasaan adanya intensitas pada perilaku yang terus menerus terjadi di dalam suatu lingkungan.

i. Kesesakan (crowdedness)

j. Privasi (privacy)

k. Makna (meaning)

1. Legibilitas (legibility)

\subsection{Adaptabilitas}

Menurut bell dalam sarwono (1991), manusia memiliki mekanisme adaptasi terhadap lingkungan yaitu;

1. adaptation by adjustment; tindakan manusia untuk menolak atau melawan lingkungan dengan cara melakukan perubahan fisik terhadap lingkungan agar terjadi kesesuaian antara manusia dengan lingkungan

2. adaptation by reaction; tindakan manusia untuk menolak atau melawan lingkungan dengan cara merubah perilaku diri agar sesuai dengan lingkungan. 
3. adaptation by widrawl: tindakan manusia untuk menghindari lingkungan dengan ketidakcocokan (ketidaksesuaian) antara manusia dengan lingkungannya dengan cara membiarkan lingkungan dan pindah ke lingkungan lain yang dianggap sesuai.

\section{Metode Penelitian}

Penelitian mengambil objek Rusunawa Panggung Harjo Sewon Bantul dalam kaitan interaksi manusia dengan lingkungan fisik (environment-behavior) dapat diteliti dari berbagai sudut pandang, sesuai dengan tujuan penelitian. Tujuan penelitian untuk mengetahui perilaku penghuni terhadap setting pedestrian Rusunawa Panggung Harjo Blok B. metodologi yang dipakai adalah kualitatif rasionalistik, dengan metoda pengumpulan data serta informasI dilakukan secara eksploratif.

\subsection{Area Penelitian}

Lokasi penelitian difokuskan pada jalur pedestrian Rusunawa Blok B Panggungharjo, Kecamatan Sewon Bantul, Yogyakarta. Rusunawa Panggungharjo terdiri dari 2 blok bangunan terpisah, berlantai lima. Pada bangunan blok B terdiri dari lantai 1 dengan 3 unit hunian yang dikhususkan bagi penyandang cacat dan lansia. Masih di bagian lantai dasar terdapat fasilitas parkir disisi timur dan barat serta ruang musola di sisi utara. Lantai 2,3, dan 4 masing masing dengan 24 unit hunian.

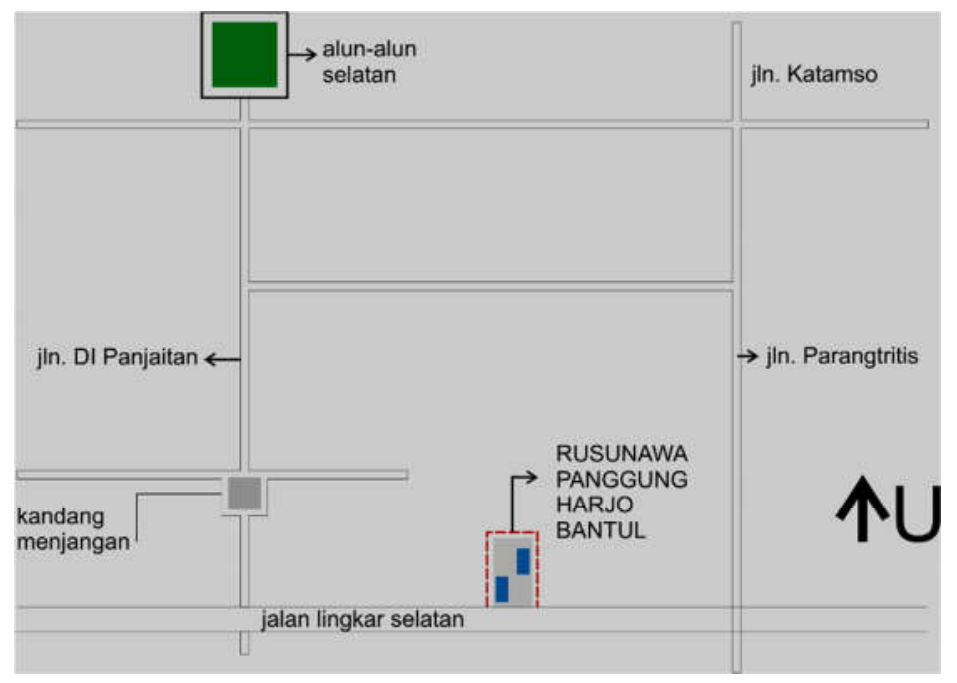

Gambar.1 Lokasi Rusunawa Panggungharjo, Bantul, Yogyakarta 


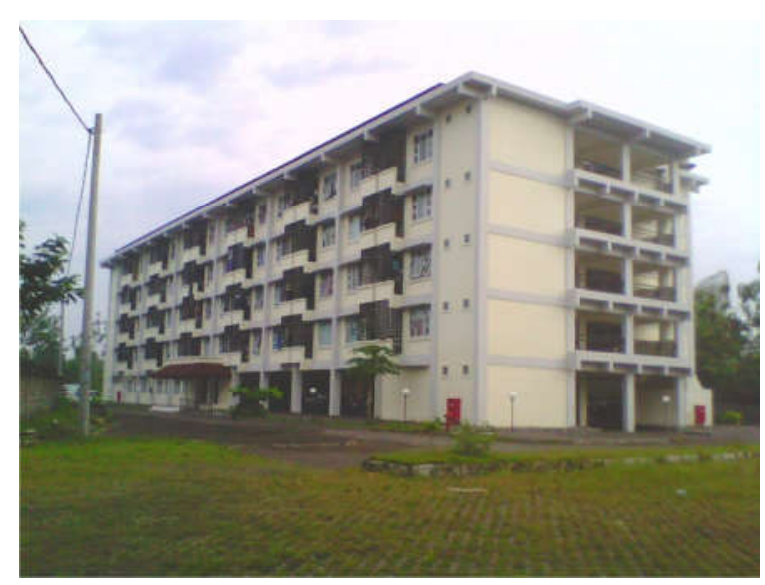

Gambar.2 Bangunan Blok B Rusunawa Panggungharjo, Bantul, Yogyakarta

\subsection{Tahapan Penelitian}

Penelitian mengambil objek Rusunawa Panggung Harjo Sewon Bantul dalam kaitan interaksi manusia dengan lingkungan fisik (environment-behavior) dapat diteliti dari berbagai sudut pandang, sesuai dengan tujuan penelitian. Tujuan penelitian untuk mengetahui perilaku penghuni terhadap setting pedestrian Rusunawa Panggung Harjo Blok B. metodologi yang dipakai adalah kualitatif rasionalistik, dengan metoda pengumpulan data serta informasI dilakukan secara eksploratif.

Ada beberapa teknik observasi yang dapat dipakai dalam kajian arsitektur lingkungan dan perilaku. Menurut (Ittelson, 1970 dalam Haryadi, 1995) teknik behavior mapping digunakan untuk mendapatkan suatu bentuk informasu mengetahui sebuah fenomena (perilaku dan setingnya). Pemetaan perilaku secara umum mengikuti prosedur yang terdiri dari lima unsur dasar, yaitu:

1. Sketsa dasar area atau seting yang akan diobservasi.

2. Defenisi yan jelas tentang bentuk-bentuk perilaku yang akan diamati, dihitung, dideskripsikan dan didiagramkan.

3. Satuan rencana waktu yang jelas pada saat kapan pengamatan akan dilakukan.

4. Prosedur sistematis yang jelas harus diikuti selama observasi

5. System coding yang efisien untuk lebih mengefisiensikan pekerjaan selama observasi.

Menurut Sommer (1980), behavior mapping digambarkan dalam bentuk sketsa atau diagam mengenai suatu area di mana manusia melakukan berbagai kegiatannya. Tujuannya adalah untuk menggambarkan perilaku kedalam peta. Mengidentifikasikan jenis dan frekuensi perilaku. Pemetaan perilaku ini dapat dilakukan secara langsung pada saat dan tempat dimana dilakukan pengamatan, atau dilakukan kemudian berdasarkan catatan-catatan yang dilakukan. Terdapat cara untuk melakukan pemetaan perilaku, yaitu: 


\section{a. Place-centered mapping}

Teknik ini digunakan untuk mengetahui bagaimana manusia atau sekelompok manusia memanfaatkan, menggunakan dan mengakomodasikan perilakunya dalam suatu waktu dan tempat tertentu. Langkah-langkah yang harus dilakukan pada teknik ini adalah:

1. membuat sketsa tempat atau setting yang meliputi serulur unsur fisik yang diperkirakan mempengaruhi perilaku

2. membuat daftar alur perilaku yang akan diamati serta menentukan simbol atau tanda sketsa atas setiap perilaku

3. Kemudian dalam kurun waktu tertentu, peneliti mencatat berbagai perilaku yang terjadi pada tempat tersebut dengan menggunakan simbol-simbol pada peta dasar yang telah disiapkan

\section{b. $\quad$ Person centered mapping}

Teknik ini menekankan pada pergerakan manusia pada periode waktu tertentu, yang berkaitan dengan tidak hanya satu tempat atau lokasi akan tetapi berbeda tempat atau lokasi. Pada place centered mapping peneliti berhadapan dengan banyak manusia, sedangkan pada person centered maping, peneliti berhadapan dengan seseorang yang khusus diamati. Langkah-langkah yang dilakukan pada teknik ini adalah:

1. menentukan jenis sampel perilaku yang akan diamati (aktor atau penggunaan ruang secara individu)

2. menentukan waktu pengamatan (pagi, siang, malam)

3. mengamati aktiviats yang dilakukan dari masing-masing sampel perilaku

4. mencatat aktivitas sampel perilaku yang diamati dalam matriks atau tabel

5. membuat alur sirkulasi sampel perilaku pada area yang diamati pada peta untuk mengetahui kemana orang pergi.

Pada teknik behavior mapping juga dikenal teknik wawancara. Jika dikaitkan dengan bidang arsitektur lingkungan dan perilaku wawancara biasanya dilakukan dengan kombinasi teknik observasi, terutama untuk menjawab pertanyaan 'mengapa (why)' suatu perilaku. Teknik observasi, khususnya observasi perilaku cenderung dilakukan juga untuk mengetahui pendapat/opini responden secara lebih luas atau menggali berbagai kemungkinan jawaban tentang mengapa dan bagimana sesuatu kejadian terjadi. Dalam penelitian arsitektur lingkungan dan perilaku, teknik ini sangat penting dilakukan terutama karena akan menjawab bagaimana mekanisme interaksi antara manusia dan lingkungan, alasan-alasan apa yang menyebabkan suatu bentuk interaksi itu terjadi. 


\section{Hasil Penelitian}

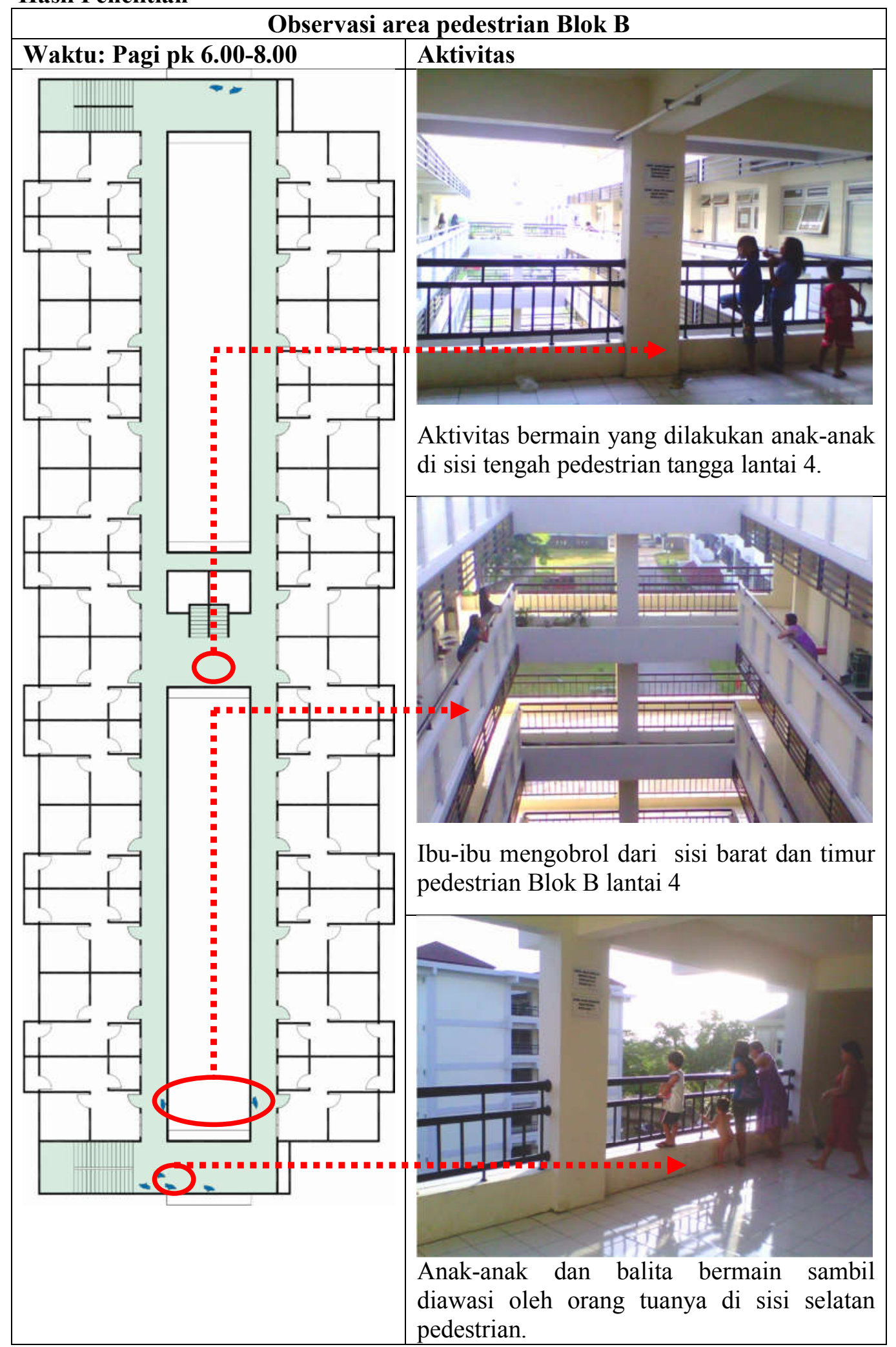




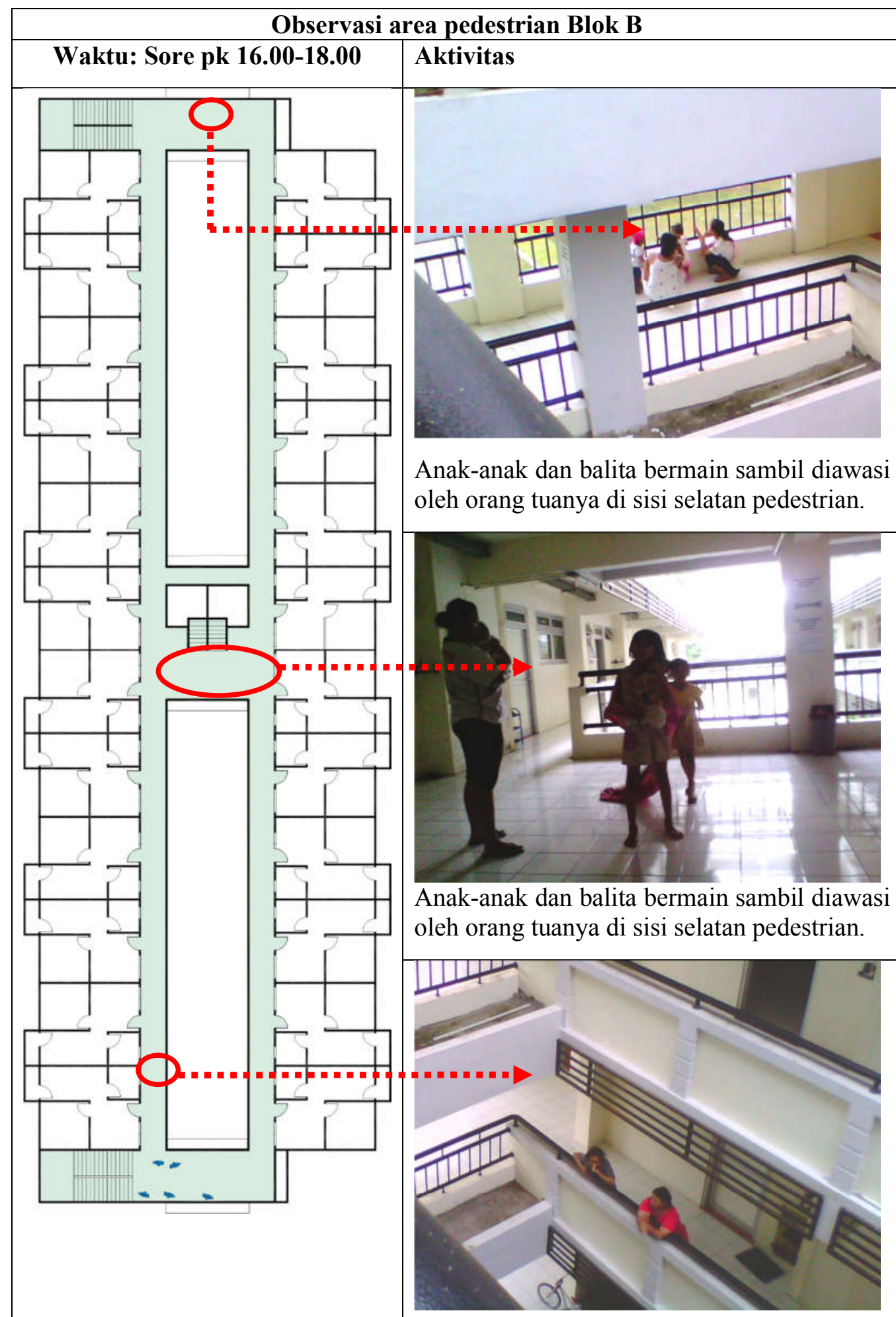

Penghuni menerima tamu dan mengobrol dari sisi barat pedestrian Blok B lantai 4 


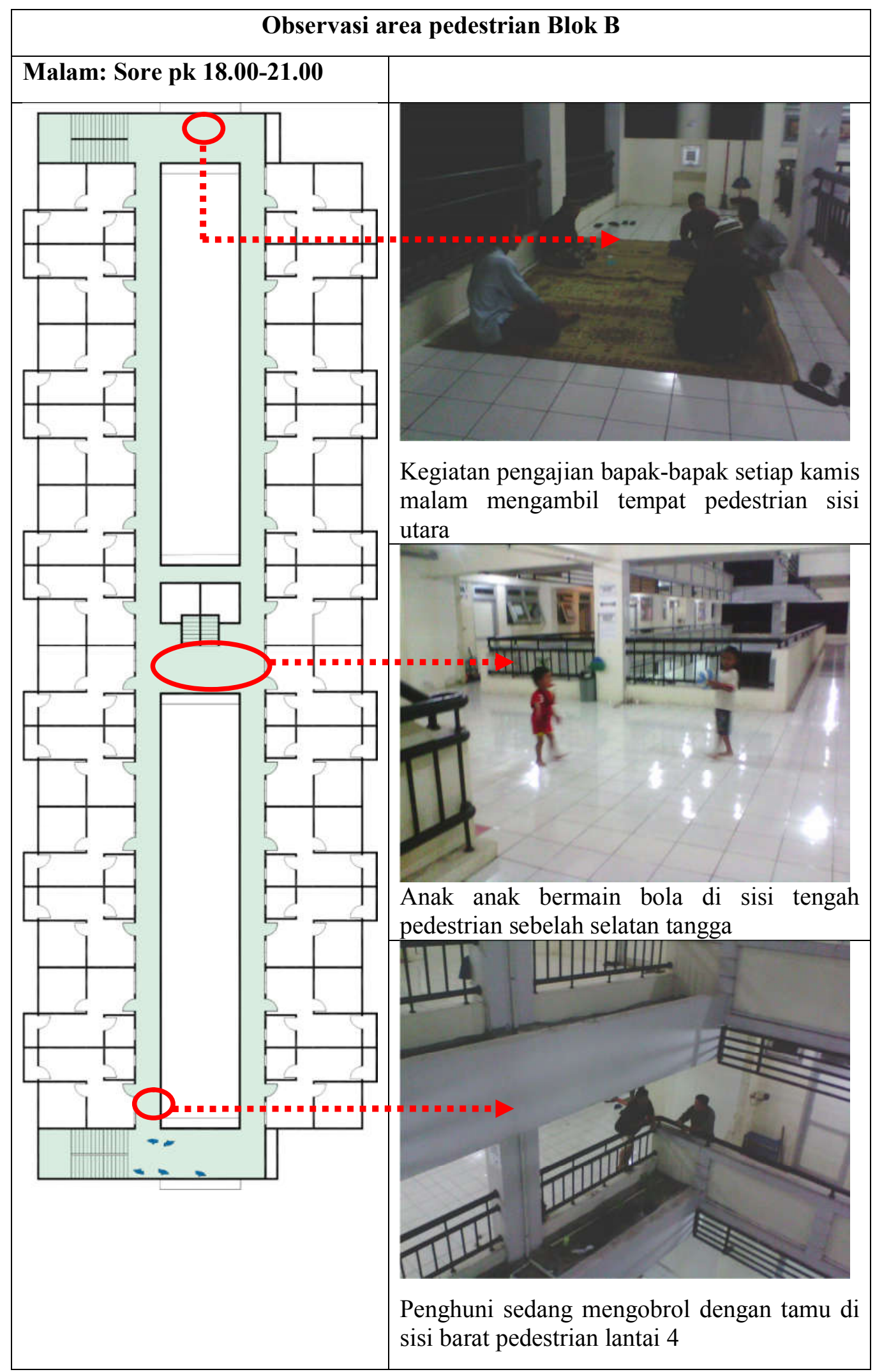


Berikut penjelasan mengenai aktivitas penghuni Rusunawa terkait adaptabilitas penghuni terhadap keterbatasan seting fisik yang ada pada jalur pedestrian

1. Aktivitas bermain

Dari hasil pengamatan aktivitas bermain anak-anak sering dilakukan di area pedestrian, anak kecil melakukan hal-hal yang berbahaya dengan memanjat pagar pembatas, hal ini terjadi karena seting fisik berupa pagar pembatas yang belum memenuhi standar keamanan jalur pedestrian. (lihat gambar 4.1 dan 4.2)

\section{Menjemur}

Keterbatasan area jemur pakaian yang ada pada bangunan, seringkali penghuni menggunakan pagar pembatas di depan unit hunian sebagai area jemur, walaupun hal ini sudah dilarang dan menjadi aturan bagi penghuni rusunawa (lihat gambar 4.3)

\section{Perletakan barang-barang}

Penghuni meletakkan barang-barang di daerah pedestrian seperti kursi, tempat sampah, sepeda anak, padahal penempatan barang-barang ini membahayakan bagi penghuni terutama untuk anak-anak. (lihat gambar 4.4, 4.5, 4.6)

\section{Kegiatan Formal}

dengan keterbatasan ruang yang pada bangunan Rusunawa penghuni menjadikan area pedestrian sebagai tempat untuk melakukan kegiatan formal, seperti pengajian rutin mingguan.

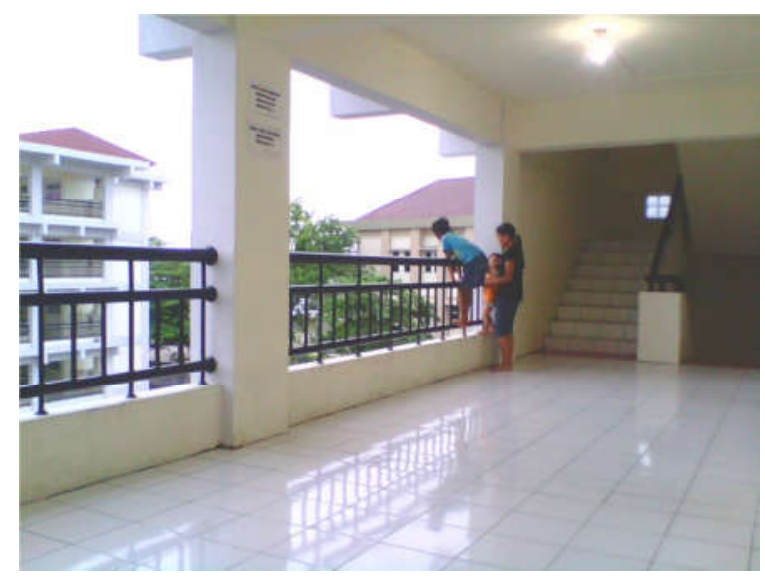

Gambar 4.1 Anak-anak memanjat pagar pembatas sisi selatan pedestrian blok B 


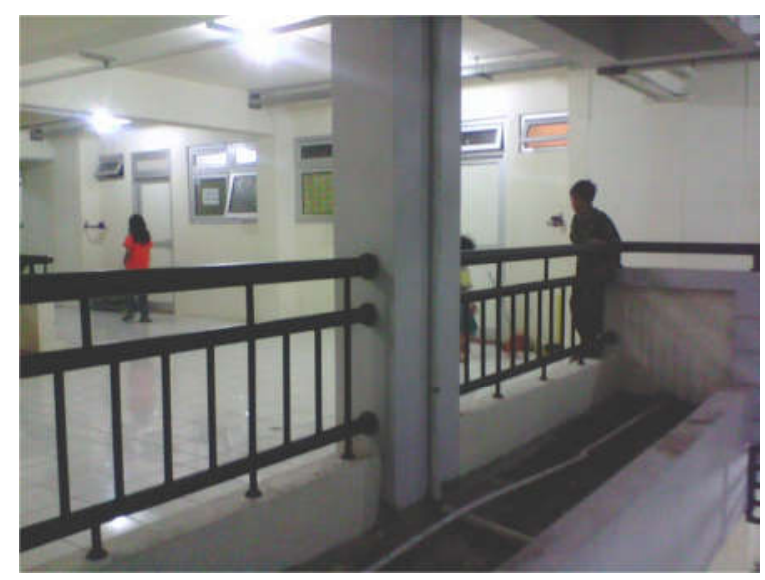

Gambar 4.2 Anak-anak memanjat pagar pembatas sisi selatan pedestrian blok B

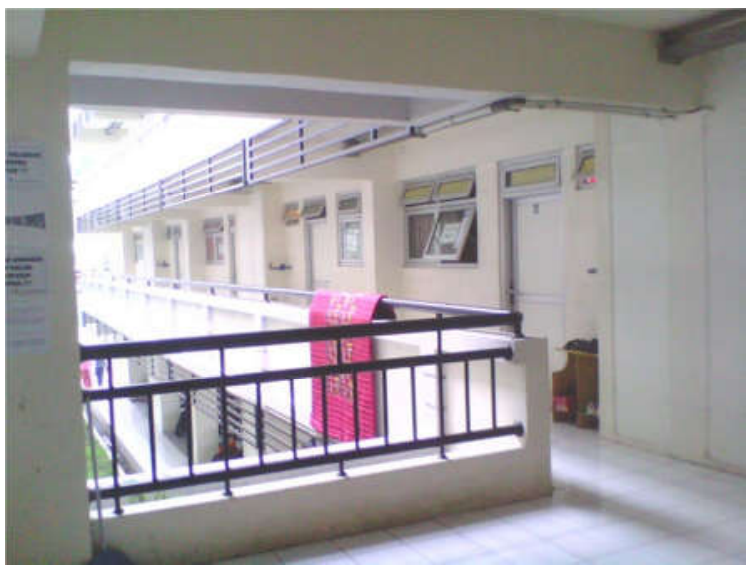

Gambar 4.3 Area pagar pembatas yang dijadikan untuk menjemur kasur

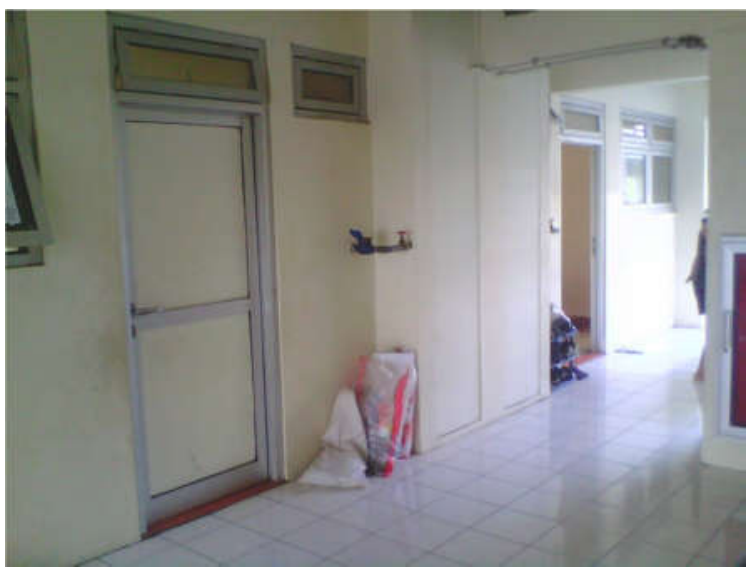

Gambar 4.4 Penempatan tempat sampah di area pedestrian. 

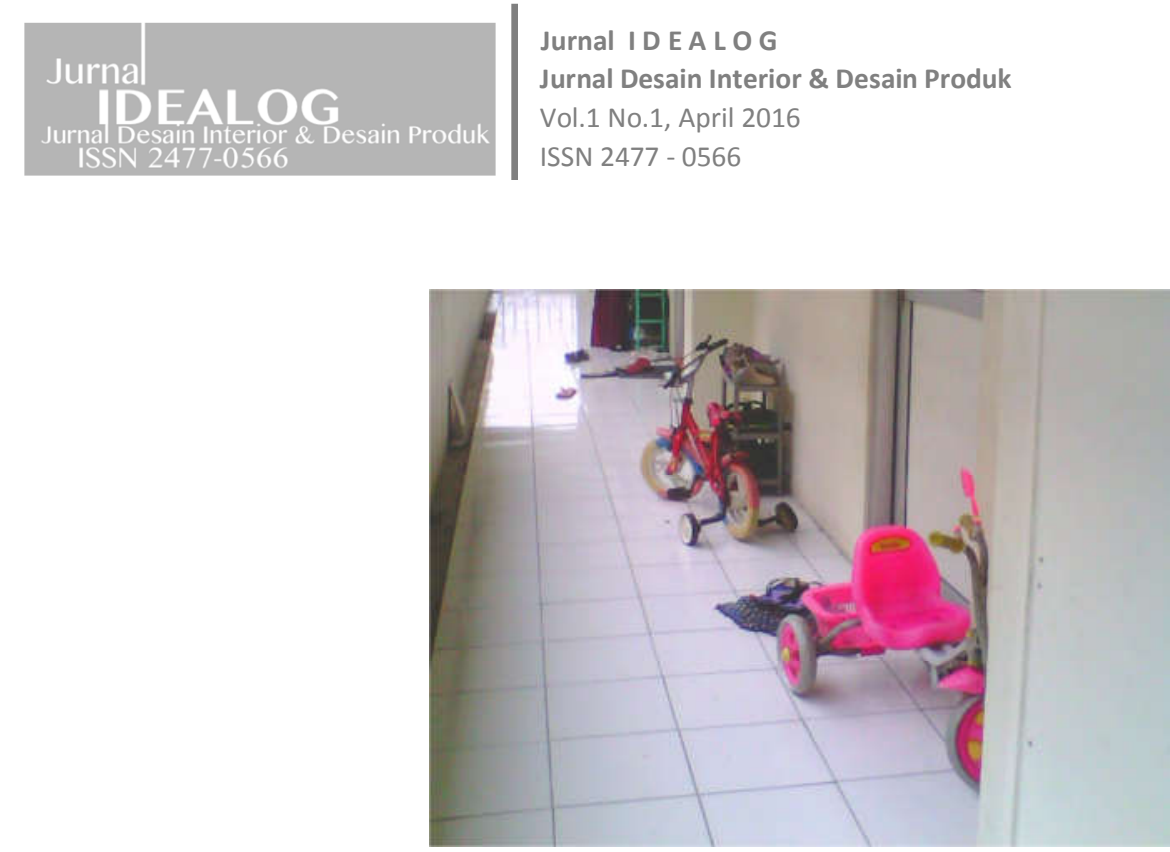

Gambar 4.5 Penempatan sepeda anak di area pedestrian.

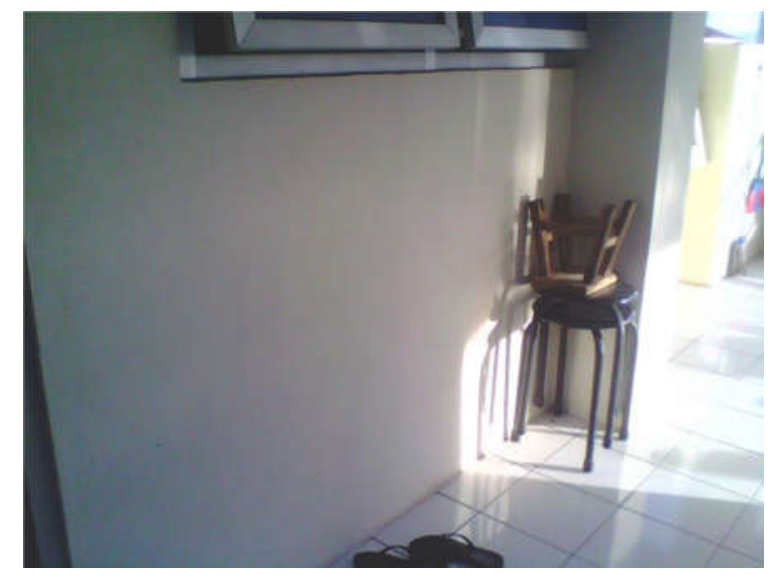

Gambar 4.6 Penempatan kursi di area pedestrian.

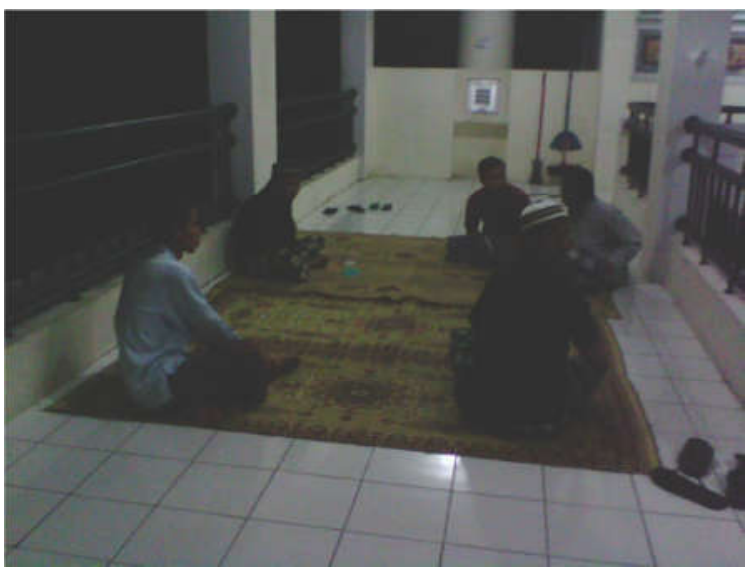

Gambar 4.7 Kegiatan pengajian bapak-bapak setiap malam Jum'at 


\section{Kesimpulan}

Adaptasi yang dilakukan penghuni terhadap seting fisik area pedestrian Rusunawa Panggungharjo Blok B yaitu;

1. Perilaku anak-anak dalam aktivitas bermain

2. Perletakan barang-barang seperti tempat sampah, sepeda, dan kursi

3. Kegiatan formal yang dilakukan di area pedestrian seperti menerima tamu dan kegiatan pengajian,

Hal tersebut merupakan wujud dari adaptation by reaction penghuni, namun tidak ada satupun dari penghuni yang melakukan adaptation by adjustmen hal ini dikarenakan kebijakan dari pengelola yang memberikan aturan dan sanksi bila melakukan perubahan fisik dalam bangunan.

Berdasarkan temuan penelitian perlu penataan ulang terkait fasilitas di masing masing lantai bangunan rusunawa agar mencukupi aktivitas penghuni terkait adaptabilitas penghuni di area pedestrian dan redesain pagar pembatas di area pedestrian yang cukup terbuka dan membahayakan bagi penghuni terutama untuk anak-anak.

\section{Daftar Pustaka}

[1] Bell, Paul A, Greene, Thomas C. Fisher Jeffry D, Baum, Andre. 1996. Environmental Psychology, $4^{\text {th }}$ rd, Florida.

[2] Darmawati, Ratna. Studi Ruang bersama dalam rumah susun bagi penghuni berpenghasilan rendah.

[3] De Chiara \& Callender, 1980. Time Saver Standard for building types $2^{\text {nd }}$ edition, Mc Graww Hill Book Company, New York.

[4] Haryadi, B Setiawan. 1995. Arsitektur Lingkungan dan Perilaku. Proyek Pengembangan Pusat Studi Lingkungan. Direktorat Jenderal Pendidikan Tinggi Departemen Pendidikan dan Kebudayaan, Republik Indonesia.

[5] Holahan, C.J. 1982. Environmental Psychology. Random House. New York.

[6] Laurents, Joyce Marcella, 2004. Arsitektur dan Perilaku Manusia. PT Grasindo, Jakarta.

[7] Weismen. 1981 Modelng Environment Behavioral System. Pennsylvania, USA.

[8] Undang-Undang Republik Indonesia, Nomor 20 Tahun 2011, Tentang Rumah Susun 